\title{
Low Physical Activity Is a Determinant for Elevated Blood Pressure in High Cardiovascular Risk Obstructive Sleep Apnea
}

\author{
Monique Mendelson PhD, Renaud Tamisier MD PhD, David Laplaud PhD, \\ Sonia Dias-Domingos MSc, Jean-Philippe Baguet MD PhD, Laurent Moreau MD, \\ Christian Koltes MD, Léonidas Chavez MD, Gilles de Lamberterie MD, Frédéric Herengt MD, \\ Patrick Levy MD PhD, Patrice Flore PhD, and Jean-Louis Pépin MD PhD
}

\begin{abstract}
INTRODUCTION: Obstructive sleep apnea (OSA) is associated with cardiovascular morbidity, including hypertension. Beyond the severity of nocturnal hypoxia, other factors such as metabolic abnormalities but also sedentary behaviors and insufficient physical activity may contribute to elevated blood pressure (BP). To clarify the respective role of these factors as determinants of BP in OSA patients, we examined the relationship between BP and anthropometrics, severity of sleep apnea, and objectively measured physical activity and sedentary behaviors. METHODS: Ninetyfive adults presenting with OSA (apnea-hypopnea index $>10$ events/h) and high cardiovascular risk $\left(63.3 \pm 8.8 \mathrm{y}\right.$; body mass index: $29.9 \pm 4.9 \mathrm{~kg} / \mathrm{m}^{2}$; apnea-hypopnea index: $41.3 \pm 17.5 / \mathrm{h}$; cardiovascular risk score: $13.5 \pm 3.7 \%$ ) were included. Physical activity and sedentary behaviors were objectively assessed by actigraphy, and self-measured home BP monitoring was measured. Logistic regression models adjusted for sex, age, and body mass index were built to identify the predictors of self-measured morning and evening BP. RESULTS: Physical activity was significantly related to obesity but not to the severity of sleep apnea or sleepiness. Sedentary behaviors were associated with self-measured morning and evening systolic $\mathrm{BP}(\mathrm{r}=\mathbf{0 . 3 2}, P=.002 ; \mathrm{r}=0.29, P=.004)$. Steps per day were inversely associated with evening $B P(r=-0.27, P=.01)$. Univariate analysis identified steps/d and time spent in vigorous physical activity as determinants for evening self-measured $B P$. In multivariate analysis, only steps/d were identified as a significant determinant of evening BP. CONCLUSIONS: Physical activity is the major determinant for evening BP in adults with OSA presenting high cardiovascular risk. Our results emphasize the need for lifestyle counseling programs in combination with CPAP to encourage regular physical activity in OSA subjects to obtain better BP control. (ClinicalTrials.gov registration NCT01226641.) Key words: obstructive sleep apnea; cardiovascular risk; blood pressure; physical activity; sedentary behaviors; sleep. [Respir Care 2014;59(8):1218-1227. (c) 2014 Daedalus Enterprises]
\end{abstract}

\section{Introduction}

Obstructive sleep apnea syndrome (OSA) has been associated with cardiovascular morbidity and, in particular,

Dr Mendelson, Dr Tamisier, Ms Dias-Domingos, Dr Levy, Dr Flore, and Dr Pépin are affiliated with Université Grenoble Alps, HP2 Laboratory, with Institut National de la Santé et de la Recherche U1042, Grenoble, and with Grenoble University Hospital, EFCR and Sleep Laboratory, Grenoble, France. Dr Laplaud is affiliated with Initiatives pour la Santé Domicile, Lyon; Dr Baguet is affiliated with the Cardiology Clinic, Centre Hospitalier Universitaire, Grenoble; Dr Moreau is affiliated with Mé- hypertension. ${ }^{1,2}$ The repetitive occurrence of apneas and hypopneas with the associated intermittent hypoxia sequence causes acute surges in blood pressure (BP), sleep fragmentation, and chronic sympathetic activation that ul-

\footnotetext{
dipôle Gentilly St Jacques, Nancy; Dr Koltes is affiliated with the Service de Pneumologie, Saint Avold; Drs Chavez and de Lamberterie are affiliated with Cabinet Marcel Benoit, Grenoble; and Dr Herengt is affiliated with Dieulefit Santé, Domaine Chamonix, Dieulefit, France.

Supplementary material related to this paper is available at http:// www.rcjournal.com.
} 
timately lead to sustained hypertension. ${ }^{3}$ A large body of evidence from animal models, intermittent hypoxia exposure of healthy humans ${ }^{4}$ and epidemiological studies support an independent role of OSA in the pathogenesis of daytime hypertension. ${ }^{2,5,6}$ However, it has been shown that CPAP, the first line therapy for OSA, has a limited effect on blood pressure control, ${ }^{7,8}$ and the size of the effect is highly related to the duration of nightly CPAP usage. ${ }^{9,10}$ This suggests that, in these frequently obese and comorbid OSA patients, the severity of abnormalities during sleep is only one of the numerous factors explaining elevated daytime blood pressure.

Lack of physical activity is an established modifiable risk factor for cardiovascular disease and premature mortality. ${ }^{11,12}$ Most studies examining physical activity and cardiovascular risk are based on subjective questionnaires, and the majority of surveys have reported higher rates of elevated blood pressure in inactive versus active individuals. ${ }^{13,14}$ One study recognizes that time spent in selfreported sedentary behaviors is a unique and independent risk factor for cardiovascular disease. ${ }^{15}$ Previous studies have also reported an association between sedentary behaviors and increased risk of hypertension. ${ }^{16,17}$ OSA severity has been associated with self-reported lack of exercise and potentially impairs exercise performance. ${ }^{18}$

Sleep duration is another modifiable risk factor that may impact BP, physical activity, and sedentary behaviors. Short-term sleep deprivation studies suggest that acute sleep deprivation increases BP. ${ }^{19,20}$ Furthermore, a relationship between habitual sleep duration and $\mathrm{BP}^{21}$ and an inverse relation between sleep duration and body mass index $(\mathrm{BMI})^{22,23}$ have been demonstrated. Hypertension in short sleepers may then also be favored by the development of obesity. ${ }^{24,25}$ One study showed that short-term sleep loss reduces daytime overall spontaneous physical activity and shifts the intensity of physical activity toward lower levels under free-living conditions. ${ }^{26}$ Accordingly, alterations in sleep quantity and quality during OSA and the associated daytime sleepiness and fatigue may be reasons for reduced physical activity and increased sedentary behaviors. ${ }^{27} \mathrm{How}-$

This study was supported by a grant from Initiative pour la Santé. The authors have disclosed no conflicts of interest.

Dr Pépin has full access to all of the data in the study, and he takes full responsibility for the integrity of all of the data and the accuracy of the data analysis, including and especially any adverse effect.

Drs Flore and Pépin are senior co-authors.

Correspondence: Monique Mendelson PhD. E-mail: monique mendelson1@gmail.com. Jean-Louis Pépin MD PhD. E-mail: jpepin@chu-grenoble.fr.

DOI: $10.4187 /$ respcare. 02948

\section{QUICK LOOK}

\section{Current knowledge}

Obstructive sleep apnea (OSA) is associated with cardiovascular morbidity including hypertension. Nocturnal hypoxia, metabolic abnormalities, sedentary behaviors, and insufficient physical activity contribute to elevated blood pressure (BP).

\section{What this paper contributes to our knowledge}

In a group of subjects with OSA and cardiovascular risk, steps/d and sedentary behaviors were the most important predictors of self-measured BP. Lifestyle counseling to improve physical activity may improve BP control.

ever, there are limited data regarding objective measures of different intensities of physical activity and sedentary behaviors and their relation to cardiovascular risk factors and blood pressure in OSA patients.

We hypothesized that daytime sleepiness, fatigue, and obesity frequently exhibited by OSA patients would lead to lower levels of physical activity and increased sedentary behavior, which, in turn, can negatively impact BP. The aim of the present study was to assess the predictors of elevated BP in OSA patients with high cardiovascular risk. Accordingly, we examined the relationship between BP and anthropometrics, severity of sleep apnea, and objectively measured physical activity and sedentary behaviors.

\section{Methods}

\section{Study Design and Participants}

Ninety-five adults with OSA were prospectively included. Inclusion criteria were: men and women 18-85 y of age, allowing a representation of OSA adults who are active in the workforce or retired and who are capable of demonstrating at least light physical activity; BMI $<40$ $\mathrm{kg} / \mathrm{m}^{2}$; OSA diagnosed with polysomnography or polygraphy; cardiovascular score $>5 \% 28$; or secondary prevention with a past history of cardiovascular disease (transient ischemic attack, stroke, cerebral hemorrhage, myocardial infarction, angina, coronary revascularization, arteriopathy, aortic aneurysm). Subjects were recruited from 13 centers across France. Mean recruitment per center was 8 subjects. Stratification was carried out to adjust the models with regards to the recruiting center. Noninclusion criteria were: central sleep apnea syndrome, cardiovascular score $<5 \%$ in primary prevention, ${ }^{28}$ cardiac failure, history of hypercapnic chronic respiratory failure, incapacitated pa- 
tients in accordance with article L 1121-6 of the French public health code, or subjects taking part in another clinical trial. The study protocol was approved by the ethical committee (Comité de Protection des Personnes Sud Est V, 09-PROR-1). All of the subjects provided written informed consent to participate in the study. The different assessments in this study corresponded to a baseline evaluation before being included in a prospective randomized, controlled trial targeting the efficiency of a telemedicine program in addition to standard CPAP treatment (Clinical Trials registration NCT01226641).

\section{Dyspnea and Fatigue Questionnaires}

Levels of fatigue over the past 6 months were measured using the 11-item Chalder fatigue scale, ${ }^{29}$ which consists of 4 items for mental fatigue and 7 items for physical fatigue. Dyspnea was evaluated with the Sadoul questionnaire. ${ }^{30}$

\section{Cardiovascular Score}

Ten-year risk of fatal cardiovascular event (Systematic Coronary Risk Evaluation Project [SCORE] calculation for European countries) was calculated. ${ }^{28}$ For data analysis, cardiovascular SCORE was automatically set at $15 \%$ if participants were in secondary prevention (ie, suffered a cardiovascular event in the past).

\section{Blood Pressure and Heart Rate Measurements}

Clinic BP was measured in the supine position by mercury sphygmomanometer on 2 occasions (2 consecutive days), with 3 measurements spaced by 1 min on each occasion, according to European guidelines on hypertension. ${ }^{31}$ Clinic heart rate was measured by pulse palpation (30 s) after the third measurement in the supine position. The following clinic parameters were assessed: systolic BP (SBP), diastolic BP (DBP), and heart rate. Office hypertension was defined as a mean (average of the 3 measurements at each of the 2 office sessions) office SBP $\geq 140 \mathrm{~mm} \mathrm{Hg}$ and/or a mean office DBP $\geq 90 \mathrm{~mm} \mathrm{Hg} .{ }^{31}$ Self-measured home BP monitoring was performed on 3 consecutive days using a validated fully automated electronic device (Omron 705CP, Omron Corporation, Tokyo, Japan). Participants were trained to use this device, and they were instructed to take 3 measures in the morning (between awakening and breakfast) and 3 measures in the evening (between dinner and bedtime) after 5 min sitting at rest and with 1-min intervals between measurements. A form was supplied to the participants to report all selfmeasured BP values. For each subject, mean of morning and evening measures was calculated. The circumference at the midpoint of the upper arm was measured, and a normal cuff was used for circumferences below $32 \mathrm{~cm}$; otherwise, a large cuff was used.

Target BPs for home readings were based on the thencurrent United Kingdom NICE guidelines for hypertension and diabetes, ${ }^{32}$ adjusted down by $10 / 5 \mathrm{~mm} \mathrm{Hg}$ in accordance with the recommendations of the British Hypertension Society (home readings tend to be lower than office readings). Target values were therefore 135/85 $\mathrm{mm} \mathrm{Hg}$ for subjects without diabetes and $125 / 80 \mathrm{~mm} \mathrm{Hg}$ for subjects with diabetes. ${ }^{32,33}$

\section{Sleep Studies}

OSA diagnosis was obtained by full polysomnography or by simplified polygraphy without electroencephalogram recordings. Sleep was scored manually according to standard criteria. Polysomnography used continuous acquisition of the following recordings: electro-oculogram ( 3 channels), electroencephalogram (3 channels), electromyogram ( 1 channel), and electrocardiogram (1 channel). Air flow was measured using nasal pressure associated with the sum of oral and nasal thermistor signals. Respiratory effort was monitored with abdominal and thoracic bands. An apnea was defined as a complete cessation of air flow for at least $10 \mathrm{~s}$ and a hypopnea as a reduction of at least $50 \%$ in the nasal pressure signal or a decrease between $30 \%$ and $50 \%$ associated with either oxygen desaturation of at least $4 \%$ or electroencephalogram arousal. Apneas were classified as obstructive, central, or mixed according to the presence or the absence of respiratory effort. The criterion for sleep apnea in this study was an apnea-hypopnea in$\operatorname{dex} \geq 10$ events/h of sleep.

\section{Accelerometer Data Collection and Analysis}

Daily physical activity was assessed using an activity monitor (Sensewear Pro2 armband, Body Media, Pittsburgh, Pennsylvania). ${ }^{34}$ The Sensewear Pro2 armband contains accelerometers that sense movement in 2 planes, a galvanic skin sensor, a temperature sensor, and a nearpatient temperature sensor. Subjects wore the activity monitor for the same period as BP monitoring (ie, $72 \mathrm{~h}$ ), allowing an estimate of mean daily physical activity by averaging data over 1 weekday and the weekend.

The intensity of activity for each minute of wear time was calculated and expressed using metabolic equivalents (METs) to determine daily time spent in sedentary, light, or moderate-to-vigorous activity. Sedentary behavior was defined as activities resulting in energy expenditure $<1.5$ METs, which is equivalent to sitting. ${ }^{35}$ Light-intensity physical activity was defined as 1.5-3 METs, moderate physical activity as 3-6 METs, vigorous physical activity as 6-9 METs and very vigorous physical activity as $>9$ 


\section{Physical Activity and Blood Pressure in OSA}

METs. This device also allows estimation of sleep duration.

\section{Statistical Analysis}

Continuous data were presented as mean $\pm \mathrm{SD}$ and categorical data as percentages (\%). Variables with $>15 \%$ of missing values were not included in the analysis. Colinearity was assessed with Pearson's or Spearman's coefficient (depending on validation of normality distribution) or Cramer's V2. Normality of the data were verified using Skewness and Kurtosis tests.

Relationship between self-measured BP and physical activity was analyzed with logistic regressions. A SBP $\geq 135 \mathrm{~mm} \mathrm{Hg}$ or a DBP $\geq 85 \mathrm{~mm} \mathrm{Hg}$ for nondiabetic subjects and a SBP $\geq 125 \mathrm{~mm} \mathrm{Hg}$ or a DBP $\geq 80 \mathrm{~mm} \mathrm{Hg}$ for diabetic subjects were considered as high levels of BP. ${ }^{32,33}$

Two sex-, age-, and BMI-adjusted linear regression models, stratified by recruiting centers, were built: one for self-measured morning BP and the other for self-measured evening BP. In the univariate logistic regression, when a continuous variable was not log-linear, it was recoded by creating a new variable from the quartiles or the median depending on the quality of information. Independent parameters were included in the multivariate model when significance was $\leq 0.1$ in the univariate model. Missing values were replaced by the median for continuous data and by the most frequent value for categorical data. A backward selection was employed for multivariate model.

Results were considered statistically significant when $P$ value was $<.05$. Statistical analysis was performed with the SAS 9.1.3 package (SAS Institute, Cary, North Carolina).

\section{Results}

\section{Study Participant Characteristics}

Subjects' characteristics are presented in Table 1. Subjects' mean age was $63.3 \pm 8.8 \mathrm{y}$, and they were predominantly male $(83.2 \%)$ and overweight or obese (BMI of $\left.29.9 \pm 4.9 \mathrm{~kg} / \mathrm{m}^{2}\right)$. By definition, subjects had high 10-y cardiovascular risk scores $(13.5 \pm 3.7 \%)$. They exhibited moderate to severe apnea-hypopnea index $(41.3 \pm 17.5 / \mathrm{h})$ with a significant amount of nocturnal hypoxia (cumulative time spent with $\mathrm{S}_{\mathrm{pO}_{2}}$ below 90\%: $14.64 \pm 19.73 \%$ ). Sleepiness as measured by the Epworth sleepiness scale was at the upper limit of the normal range $(8.0 \pm 4.4)$. Sleep duration estimated at home on 3 different nights by accelerometer was $353.7 \pm 85.1 \mathrm{~min}(5.9 \pm 1.4 \mathrm{~h})$ (Table 2$)$.

\section{Physical Activity and Sedentary Behaviors}

Average number of steps/d was 7,393 $\pm 3,545$, and mean daily energy expenditure was 2,622.6 $\pm 515.9 \mathrm{kcal}$ (Table
Table 1. Anthropometric, Clinical, and Polysomnographic Characteristics

\begin{tabular}{|c|c|}
\hline Clinical Data & Mean $\pm \mathrm{SD}($ range $)(N=95)$ \\
\hline Age (y) & $63.3 \pm 8.8(40.0-82.0)$ \\
\hline Gender (men, \%) & $79(83.2)$ \\
\hline BMI $\left(\mathrm{kg} / \mathrm{m}^{2}\right)$ & $29.9 \pm 4.9(21.0-45.0)$ \\
\hline $\mathrm{BMI}<25 \mathrm{~kg} / \mathrm{m}^{2}(n, \%)$ & $12(12.6)$ \\
\hline $25<\mathrm{BMI}<30 \mathrm{~kg} / \mathrm{m}^{2}(n, \%)$ & $40(42.1)$ \\
\hline $30<\mathrm{BMI}<35 \mathrm{~kg} / \mathrm{m}^{2}(n, \%)$ & $29(30.5)$ \\
\hline $35<\mathrm{BMI}<40 \mathrm{~kg} / \mathrm{m}^{2}(n, \%)$ & $11(11.6)$ \\
\hline $\mathrm{BMI}>40 \mathrm{~kg} / \mathrm{m}^{2}(n, \%)$ & $3(3.1)$ \\
\hline $\begin{array}{l}\text { Office systolic blood pressure } \\
\quad(\mathrm{mm} \mathrm{Hg})\end{array}$ & $138.4 \pm 18.4(108.0-200.0)$ \\
\hline $\begin{array}{l}\text { Office diastolic blood pressure } \\
\quad(\mathrm{mm} \mathrm{Hg})\end{array}$ & $80.7 \pm 12.4(57.0-120.0)$ \\
\hline Type 2 diabetes (\%) & 34.0 \\
\hline $\begin{array}{l}\text { Smoker (never:current:former; } \\
\quad n, \%)\end{array}$ & 32 (33.7): 15 (15.8): $48(50.5)$ \\
\hline Alcohol (units/d) & $1.2 \pm 1.7(0-7.0)$ \\
\hline Cardiovascular risk score (\%) & $13.5 \pm 3.7(5.0-27.6)$ \\
\hline $\begin{array}{l}\text { Patients in secondary prevention } \\
\quad(n, \%)\end{array}$ & $57(60)$ \\
\hline \multicolumn{2}{|l|}{ Home self-measured blood pressure } \\
\hline $\begin{array}{l}\text { Morning systolic blood pressure } \\
\quad(\mathrm{mm} \mathrm{Hg})\end{array}$ & $135.2 \pm 13.7(105.9-164.0)$ \\
\hline $\begin{array}{l}\text { Morning diastolic blood pressure } \\
\quad(\mathrm{mm} \mathrm{Hg})\end{array}$ & $81.3 \pm 9.7(60.8-122.1)$ \\
\hline $\begin{array}{l}\text { Evening systolic blood pressure } \\
\quad(\mathrm{mm} \mathrm{Hg})\end{array}$ & $130.5 \pm 15.3(102.3-174.9)$ \\
\hline $\begin{array}{l}\text { Evening diastolic blood pressure } \\
\quad(\mathrm{mm} \mathrm{Hg})\end{array}$ & $77.1 \pm 9.5(46.8-105.0)$ \\
\hline \multicolumn{2}{|l|}{ Lipid profile } \\
\hline Total cholesterol (mmol/L) & $4.71 \pm 1.13(2.66-7.79)$ \\
\hline $\mathrm{HDL}(\mathrm{mmol} / \mathrm{L})$ & $1.29 \pm 0.53(0.37-4.14)$ \\
\hline $\mathrm{LDL}(\mathrm{mmol} / \mathrm{L})$ & $2.56 \pm 1.06(0.81-5.33)$ \\
\hline Fasting glucose (g/L) & $1.13 \pm 0.32(0.51-2.63)$ \\
\hline Epworth sleepiness score & $8.0 \pm 4.4(0-20.0)$ \\
\hline \multicolumn{2}{|l|}{ Chalder fatigue scale } \\
\hline Physical symptoms & $16.2 \pm 3.6(7.0-28.0)$ \\
\hline Mental symptoms & $9.1 \pm 1.9(5.0-15.0)$ \\
\hline Sadoul dyspnea score & $41.3 \pm 17.5(0-5.0)$ \\
\hline \multicolumn{2}{|l|}{ Sleep studies } \\
\hline AHI (No. of events/h of sleep) & $41.3 \pm 17.5(10.2-98.6)$ \\
\hline Mean nocturnal $\mathrm{S}_{\mathrm{pO}_{2}}(\%)$ & $92.4 \pm 2.4(83.0-96.0)$ \\
\hline Minimum nocturnal $\mathrm{S}_{\mathrm{pO}_{2}}(\%)$ & $78.5 \pm 8.5(49.0-92.0)$ \\
\hline $\mathrm{CT}_{90}(\%)$ & $14.6 \pm 19.7(0-85.0)$ \\
\hline $\begin{array}{l}\mathrm{BMI}=\text { body mass index } \\
\mathrm{HDL}=\text { high density lipoprotein } \\
\mathrm{LDL}=\text { low density lioprotein } \\
\mathrm{AHI}=\text { apnea hypopnea index } \\
\mathrm{CT}_{90}(\%)=\text { cumulative time spent with } \mathrm{S}_{\mathrm{pO}_{2}} \text { bel }\end{array}$ & $90 \%$ (\% of time of recording) \\
\hline
\end{tabular}

2). Average daily MET levels were $1.3 \pm 0.3$, which is significantly $<1.5$ (ie, the cut-off point below which sedentary behavior is defined). ${ }^{35}$ Time periods spent in sedentary behaviors, light physical activity, and moderate physical activity were $736.3 \pm 138.6,224.1 \pm 90.9$, and 95.1 
Table 2. Physical Activity Measurements

\begin{tabular}{lc}
\hline \hline \multicolumn{1}{c}{ Measurements } & $\begin{array}{c}\text { Mean } \pm \text { SD (range) } \\
(N=95)\end{array}$ \\
\hline $\begin{array}{l}\text { Energy expenditure (kcal) } \\
\text { Steps/d ( } n)\end{array}$ & $2,622.6 \pm 515.9(1,625.0-3,892.0)$ \\
Average METs & $7,393.0 \pm 3,544.8(801.0-17,761.0)$ \\
Exercise intensity & $1.3 \pm 0.3(0.8-2.4)$ \\
Total time in sedentary & \\
$\quad$ behaviors (0-1.5 METs, \\
$\quad$ min)
\end{tabular}

$\pm 86.5 \mathrm{~min}$, respectively $(12.7 \pm 2.3 ; 3.7 \pm 1.5$, and 1.6 $\pm 1.5 \mathrm{~h}$, respectively) (Table 2 ).

\section{Association Between Obesity and Sleep Apnea Severity and Physical Activity and Sedentary Behaviors}

Body mass index was inversely correlated with steps/d $(\mathrm{r}=-0.28, P=.007)($ Fig. 1$)$ and daily METs $(\mathrm{r}=-0.43$, $P<.001)$. Steps/d did not correlate with sleepiness or other indices of OSA severity (Fig. 2, ESS in panel A and mean nocturnal $\mathrm{S}_{\mathrm{pO}_{2}}$ in panel B).

\section{Association of Physical Activity and Sedentary Behaviors With BP}

Total energy expenditure was inversely correlated with office DBP $(\mathrm{r}=-0.22, P=.037)$. Steps/d were inversely correlated with evening self-measured SBP $(\mathrm{r}=-0.27$, $P=.01$ ) (Fig. 3A) but not morning self-measured BP. Time spent in sedentary behaviors $(0-1.5$ METs) was positively associated with self-measured morning and evening SBP (Fig. 3B) and DBP ( $\mathrm{r}=0.32, P=.002 ; \mathrm{r}=0.28$, $P=.006$ and $\mathrm{r}=0.29, P=.004 ; \mathrm{r}=0.27, P=.009$, respectively).

\section{Determinants of Blood Pressure}

Morning BP. Univariate analysis, adjusted for age, sex, and BMI and stratified for recruiting center, identified

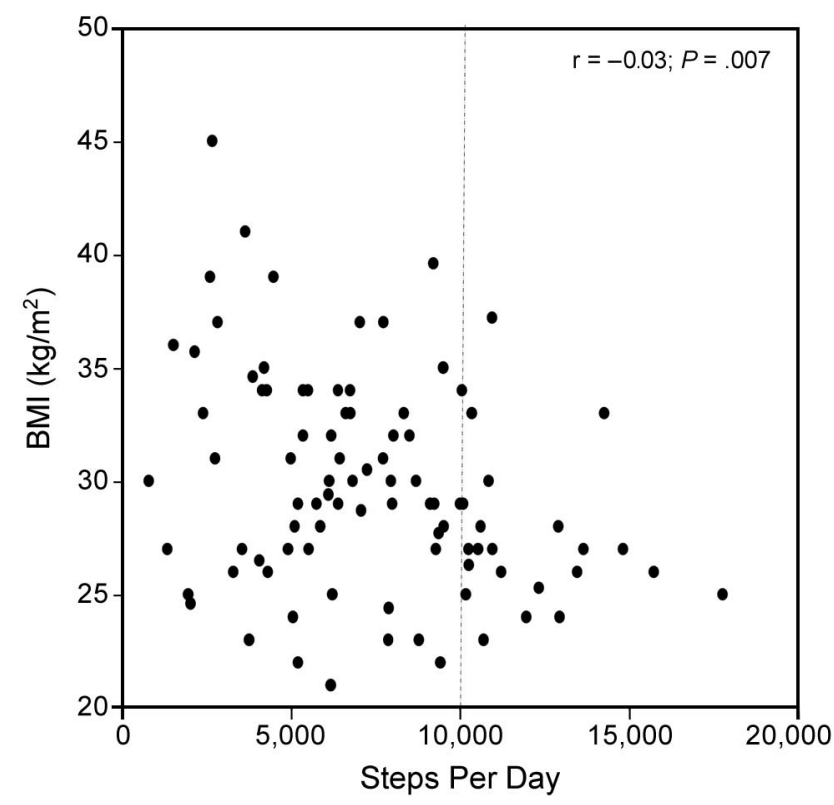

Fig. 1. Correlation between body mass index (BMI) and steps/d. The dotted line represents the recommended level of steps/d for optimal health. ${ }^{36}$

cardiovascular SCORE, and cumulative time spent with $\mathrm{S}_{\mathrm{pO}_{2}}$ below $90 \%$ as significant determinants for morning self-measured BP (see Table S1 in the supplementary materials at http://www.rcjournal.com). In multivariate analysis, secondary prevention was associated with morning selfmeasured $\mathrm{BP}$ in the normal range (odds ratio [OR], 0.22, 95\% CI, 0.05-0.93, $P=.039$ ), whereas alcohol consumption was associated with higher values of self-measured BP (OR, $10.43,95 \%$ CI, 2.36-46.04, $P=.002$ ).

Evening BP. In univariate analysis, cardiovascular risk SCORE, cumulative time spent with $\mathrm{S}_{\mathrm{pO}_{2}}$ below $90 \%$, number of steps/d, and time spent in very vigorous physical activity ( $>9$ METs) were linked with evening self-measured BP in the normal range (see Table S1 in the supplementary materials at http://www.rcjournal.com). On the other hand, time spent in sedentary behaviors, BMI, type 2 diabetes, and high scores for Sadoul and Chalder scales were identified as determinants of elevated evening selfmeasured BP. Smoking was not identified as a predictor of elevated morning or evening BP.

Multivariate analysis identified cardiovascular score $>15 \%$ (OR, 0.20, 95\% CI, 0.04-0.96, $P=.044$ ) and number of steps/d (for 6,932.5 $<$ steps $/ \mathrm{d}<10,012$ vs $<4,974.5$ steps $/ \mathrm{d}$ : OR, $0.15,95 \%$ CI, 0.02-0.89, $P=.037$ ) and (for steps/d $\geq 10,012$ vs $<4,974.5$ : OR, $0.14,95 \% \mathrm{CI}, 0.02-0.86$, $P=.034)$ as significant determinants of evening self-measured BP in the normal range (Fig. 4). Presence of diabetes was associated with elevated evening self-measured $\mathrm{BP}(\mathrm{OR}$, 7.37, 95\% CI, 1.71-31.73, $P=.007)$. 
A

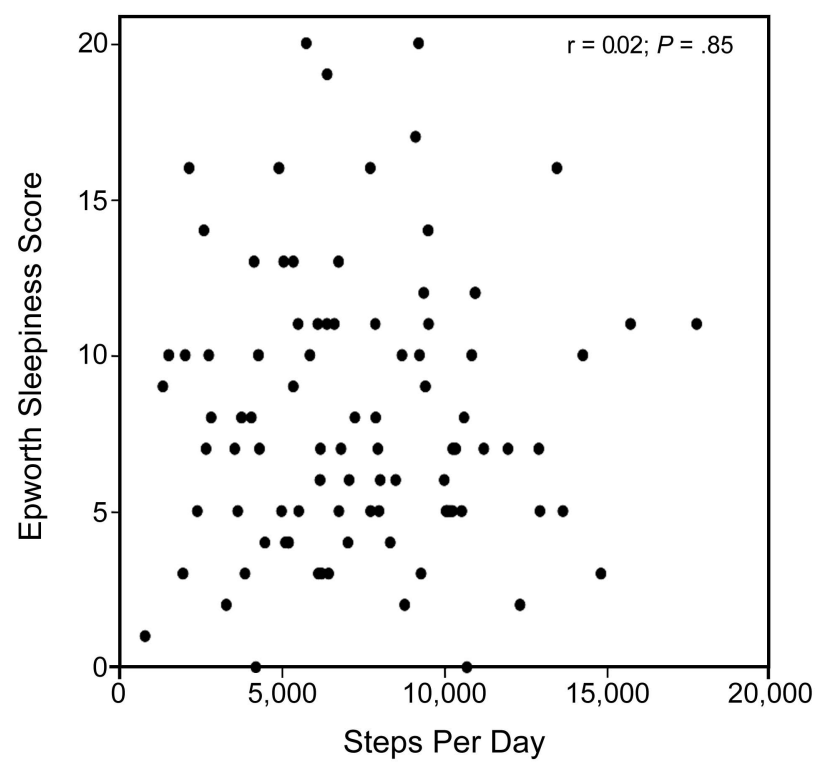

B

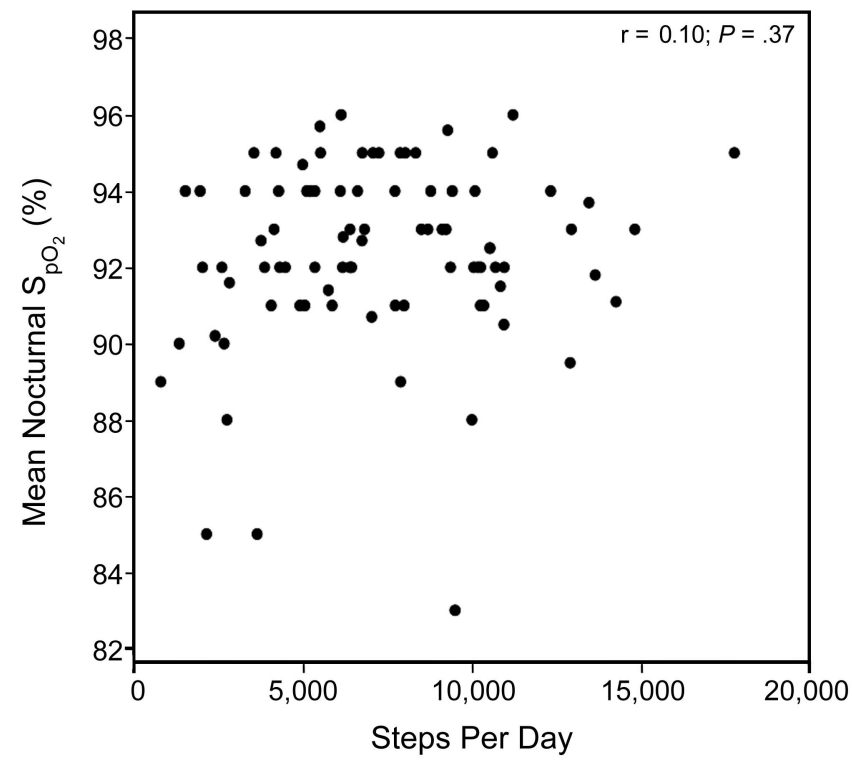

Fig. 2. A: Epworth sleepiness score; B: mean nocturnal oxygen saturation $\left(\mathrm{S}_{\mathrm{apO}_{2}}\right)$ plotted against steps/d.
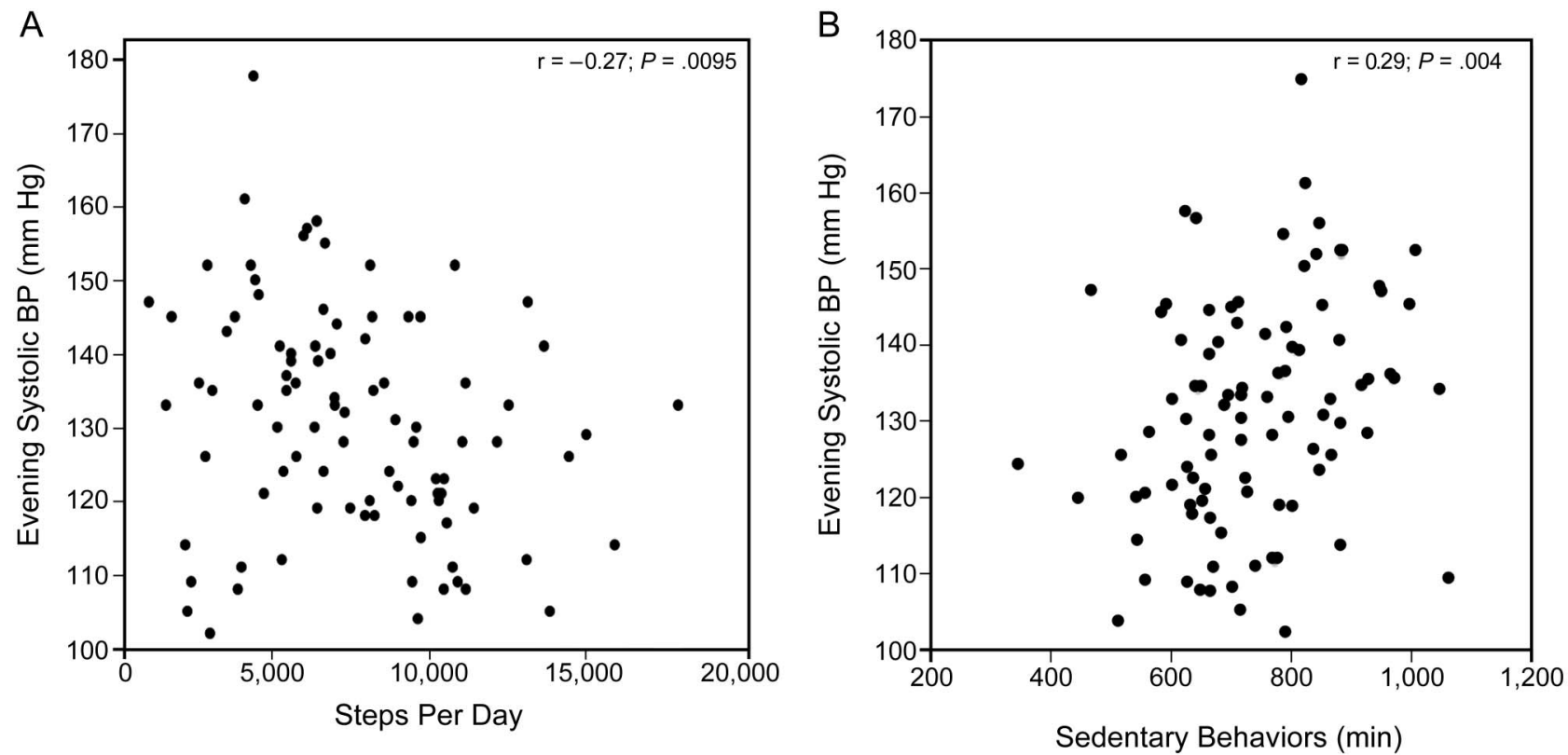

Fig. 3. A: correlation between steps/d and self-measured evening systolic blood pressure (SBP); B: correlation between time spent in sedentary behavior and self-measured evening SBP.

\section{Discussion}

In adults with OSA presenting high cardiovascular risk, physical activity is reduced and below consensus recommendations for optimal health. The level of physical activity is significantly related to the degree of obesity but not linked with the severity of sleep apnea or sleepiness. The main finding of our study was that steps/d and sed- entary behaviors are the most important predictors of evening self-measured BP. Thus, in individuals with OSA, daily physical activity impacts BP levels but with a different magnitude in the morning and evening. Selfmeasured BP measures were performed, as this type of measure seems to have a stronger predictive power for future cardiovascular events. ${ }^{37}$ Both morning and evening home BP have been shown to be positively asso- 


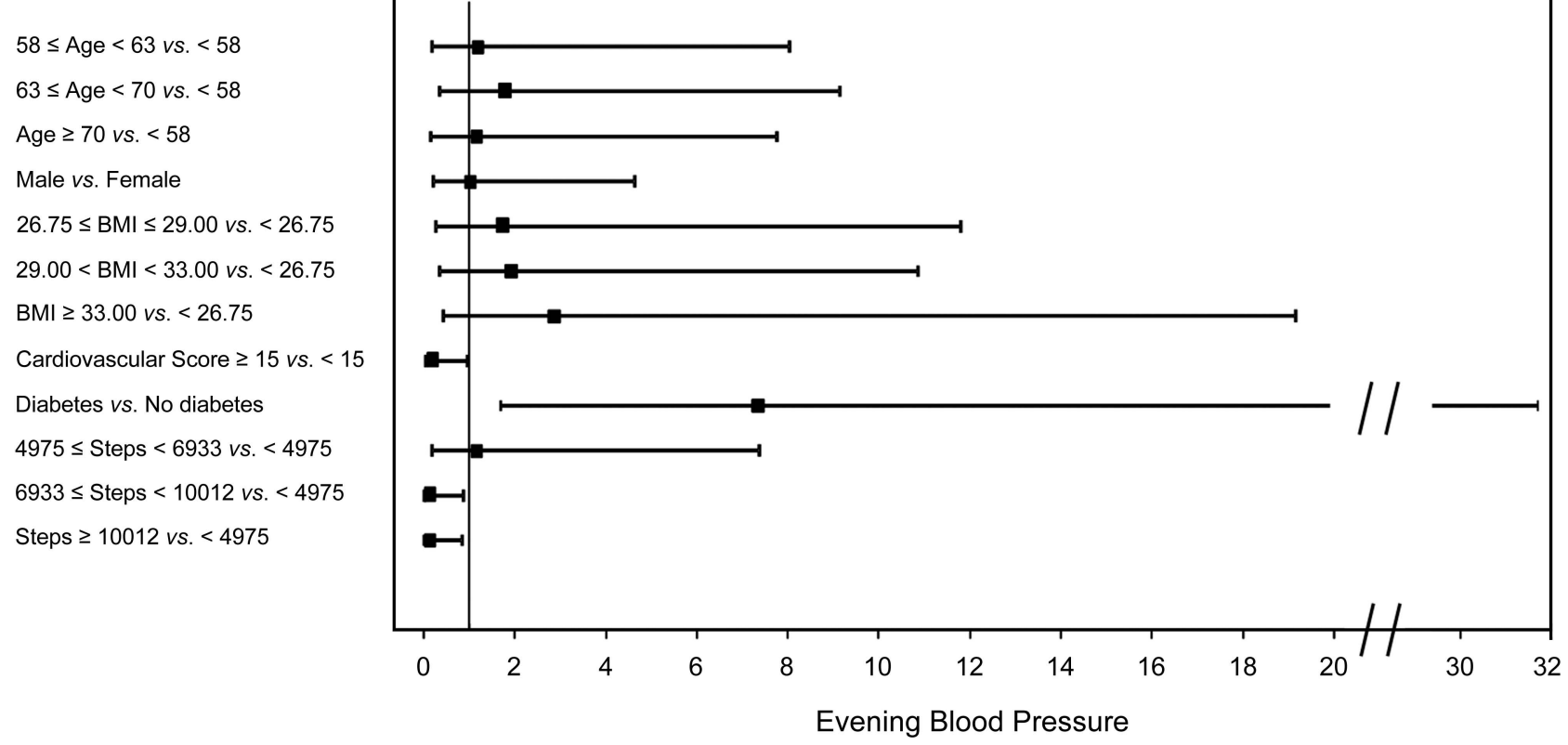

Fig. 4. Multivariate analysis for self-measured evening blood pressure. Odds ratios and $95 \% \mathrm{Cl}$ are depicted. BMI = body mass index.

ciated with the incidence of stroke, ${ }^{37,38}$ indicating that evening BP has clinical relevance. Thus, in the present study, we created 2 univariate models: for morning and evening BP.

Our study is the first to examine the relationship between objective measures of physical activity and sedentary behaviors and home self-measured BP in high cardiovascular risk OSA subjects. Only 2 previous studies in the field have reported interesting but more limited data on higher energy expenditure during sleep ${ }^{39}$ or mean activity in arbitrary units. ${ }^{39}$ Interestingly, physical activity was not increased by CPAP treatment, suggesting that OSA per se is not the main contributor to reduced physical activity levels..$^{40}$ In our study, we measured physical activity patterns with an accelerometer validated in healthy subjects ${ }^{41}$ and in diabetics. ${ }^{34}$ This device, which has also been recently validated in OSA during sleep, ${ }^{39}$ is considered one of the most reliable means of estimating physical activity and its patterns in free living conditions. ${ }^{42,43}$ In a study comparing the validity of 6 activity monitors, the SenseWear Armband (a biaxial monitor) was 1 of the 2 most valid monitors during standardized physical activities. ${ }^{44}$ A major strength of our study was to provide objective measures of sedentary behaviors concurrently to home self-measurement of BP. The recommended duration for such a BP assessment is $72 \mathrm{~h}, 45$ and we decided to correlate physical activity and BP measurement in this time window. We do, however, acknowledge that averaging measures from a 7 -d period would have been ideal. Another strength and originality of this study is that BP was assessed by home selfmeasurement of BP, which is now accepted as a better predictor of target organ damages and even incident cardiovascular events compared with office measurements of BP. ${ }^{46}$

Study participants were representative of a typical middle-aged, male OSA population with co-morbidities. ${ }^{5,47}$ Sleepiness for the whole group was at the upper limit of the normal range. OSA patients also suffering from associated cardiovascular diseases ${ }^{48}$ or diabetes ${ }^{49}$ tend to not complain from sleepiness but rather of fatigue or dyspnea. Only $25 \%$ of the included subjects reached recommended levels of physical activity (10,000 steps/d). There was an inverse correlation between the number of steps/d and BMI consistent with the well-documented inverse relationship between physical activity and weight gain. ${ }^{50} \mathrm{~A}$ previous study that assessed physical activity by questionnaires found that physical activity was a stronger predictor of perceptions of fatigue and energy than OSA severity. ${ }^{27}$ These results contrast with our study, in which subjective sleepiness was not associated with spontaneous physical activity. As questionnaires are known to be subject to widely varying bias, ${ }^{51}$ our study has the advantage of providing objectively measured spontaneous physical activity in individuals with OSA.

\section{Blood Pressure: Respective Role of Physical Activity and OSA}

Approximately $60 \%$ of individuals with OSA exhibit daytime hypertension. ${ }^{52}$ The dose-response relationship between the severity of OSA and the incidence of hypertension has been clearly demonstrated both in the general 
population ${ }^{2}$ and in clinical cohorts. ${ }^{1}$ OSA is now acknowledged as a cause of hypertension in European and American guidelines on hypertension management. ${ }^{31,53}$ However, it has been shown that CPAP intervention only has a limited effect on BP control with pooled mean changes of $-2.46 \mathrm{~mm} \mathrm{Hg}$ in SBP and $-1.83 \mathrm{~mm} \mathrm{Hg}$ in 24-h DBP. ${ }^{7}$ This suggests that OSA per se, which is frequently associated with obesity, is only one of the many potential contributors to uncontrolled BP. In the multivariate analysis of morning self-measured BP, only alcohol consumption and diabetes were identified as determinants for hypertension. Secondary cardiovascular prevention was associated with lower morning self-measured BP. The relation between hypertension and excess alcohol consumption and diabetes is well established. ${ }^{54}$ Among the potential contributors to elevated BP are sedentary behaviors, which have emerged as an independent risk factor for cardiovascular disease. ${ }^{55}$ In the present study, sedentary behaviors were positively associated with self-measured morning and evening SBP and DBP. Furthermore, univariate analysis identified time spent in sedentary behaviors as a determinant of elevated evening self-measured BP. Our results are supported by a prospective cohort study in which self-reported total sedentary behaviors were directly associated with a higher risk of incident hypertension. ${ }^{17}$

In our study, multivariate analysis identified steps/d as a determinant of lower evening self-measured BP. A population-based study showed that leisure activity at different life stages was associated with lower SBP and DBP in mid-adulthood by $\sim 1-2 \mathrm{~mm} \mathrm{Hg}$ and with reduced risk of hypertension by $\sim 23 \%$ (active vs nonactive), although this reduction was influenced by age. ${ }^{56}$

\section{Study Limitations}

This study could have benefited from a control group, which would have allowed the study to establish whether the same determinants impact BP in individuals presenting high cardiovascular risk without OSA. It would have been interesting to measure dietary patterns of participants in the present study to establish whether certain dietary habits contributed to elevated BP, as several epidemiological surveys have suggested that diet is an important factor in modulating BP. ${ }^{57}$

\section{Practical Implications in the Management of OSA Patients}

In our final multivariate model, only steps/d were identified as a determinant for lower evening self-measured BP. Steps per day can be measured simply with a pedometer, which is far less expensive than the accelerometer we used in the present study. The emergent body of evidence suggests that pedometer-determined physical activity is related to a number of cardiovascular health outcomes. ${ }^{58}$ Pedometers may prove a more financially viable option to increase physical activity levels and concomitantly reduce sedentary behavior. Simpler recommendations such as increasing steps/d, ideally to $10,000 / \mathrm{d}$, can be easily integrated in daily life activities (transport, domestic tasks) and should be implemented as a combined therapy with CPAP treatment. Moreover, as the effects of CPAP on cardiometabolic markers are minimal, ${ }^{58,59}$ any increase in physical activity will positively impact on lipid and glucose metabolism abnormalities.

\section{Conclusions}

Thus, for individuals with OSA presenting high cardiovascular risk, a combined approach integrating CPAP and lifestyle interventions including physical activity programs would improve BP control and, in turn, potentially reduce mortality. Regular physical activity can also enhance the effects of CPAP therapy, as it has been associated with reduced incidence and severity of sleep-disordered breathing in longitudinal and cross-sectional studies. ${ }^{60-63}$

\section{REFERENCES}

1. Marin JM, Agusti A, Villar I, Forner M, Nieto D, Carrizo SJ, et al. Association between treated and untreated obstructive sleep apnea and risk of hypertension. JAMA 2012;307(20):2169-2176.

2. Peppard PE, Young T, Palta M, Skatrud J. Prospective study of the association between sleep-disordered breathing and hypertension. N Engl J Med 2000;342(19):1378-1384.

3. Lévy P, Pépin JL, Arnaud C, Baguet JP, Dematteis M, Mach F. Obstructive sleep apnea and atherosclerosis. Prog Cardiovasc Dis 2009;51(5):400-410.

4. Tamisier R, Pépin JL, Rémy J, Baguet JP, Taylor JA, Weiss JW, Lévy P. 14 nights of intermittent hypoxia elevate daytime blood pressure and sympathetic activity in healthy humans. Eur Respir J 2011;37(1):119-128.

5. Cano-Pumarega I, Durán-Cantolla J, Aizpuru F, Miranda-Serrano E, Rubio R, Martínez-Null C, et al. Obstructive sleep apnea and systemic hypertension: longitudinal study in the general population; the Vitoria Sleep Cohort. Am J Respir Crit Care Med 2011;184(11): 1299-1304.

6. O'Connor GT, Caffo B, Newman AB, Quan SF, Rapoport DM, Redline S, et al. Prospective study of sleep-disordered breathing and hypertension: the Sleep Heart Health Study. Am J Respir Crit Care Med 2009;179(12):1159-1164.

7. Bazzano LA, Khan Z, Reynolds K, He J. Effect of nocturnal nasal continuous positive airway pressure on blood pressure in obstructive sleep apnea. Hypertension 2007;50(2):417-423.

8. Haentjens P, Van Meerhaeghe A, Moscariello A, De Weerdt S, Poppe K, Dupont A, Velkeniers B. The impact of continuous positive airway pressure on blood pressure in patients with obstructive sleep apnea syndrome: evidence from a meta-analysis of placebocontrolled randomized trials. Arch Intern Med 2007;167(8):757-764.

9. Barbé F, Durán-Cantolla J, Capote F, de la Peña M, Chiner E, Masa JF, et al. Long-term effect of continuous positive airway pressure in hypertensive patients with sleep apnea. Am J Respir Crit Care Med 2010;181(7):718-726. 


\section{Physical Activity and Blood Pressure in OSA}

10. Pépin JL, Tamisier R, Barone-Rochette G, Launois SH, Lévy P, Baguet JP. Comparison of continuous positive airway pressure and valsartan in hypertensive patients with sleep apnea. Am J Respir Crit Care Med 2010;182(7):954-960.

11. Haskell WL, Lee IM, Pate RR, Powell KE, Blair SN, Franklin BA, et al. Physical activity and public health: updated recommendation for adults from the American College of Sports Medicine and the American Heart Association. Circulation 2007;116(9):1081-1093.

12. Wen CP, Wai JPM, Tsai MK, Yang YC, Cheng TY, Lee MC, et al. Minimum amount of physical activity for reduced mortality and extended life expectancy: a prospective cohort study. Lancet 2011; 378(9798):1244-1253.

13. Bassett DR Jr, Fitzhugh EC, Crespo CJ, King GA, McLaughlin JE. Physical activity and ethnic differences in hypertension prevalence in the United States. Prev Med 2002;34(2):179-186.

14. Pereira MA, Folsom AR, McGovern PG, Carpenter M, Arnett DK, Liao D, et al. Physical activity and incident hypertension in black and white adults: the Atherosclerosis Risk in Communities Study. Prev Med 1999;28(3):304-312.

15. Owen N, Healy GN, Matthews CE, Dunstan DW. Too much sitting: the population health science of sedentary behavior. Exerc Sport Sci Rev 2010;38(3):105-113.

16. Aadahl M, Kjaer M, Jørgensen T. Influence of time spent on TV viewing and vigorous intensity physical activity on cardiovascular biomarkers: the Inter 99 study. Eur J Cardiovasc Prev Rehabil 2007; 14(5):660-665.

17. Beunza JJ, Martínez-González MA, Ebrahim S, Bes-Rastrollo M, Núñez J, Martínez JA, Alonso A. Sedentary behaviors and the risk of incident hypertension: the SUN Cohort. Am J Hypertens 2007;20(11): 1156-1162.

18. Cintra F, Poyares D, Rizzi CF, Risso TT, Skomro R, Montuori E, et al. Cardiorespiratory response to exercise in men and women with obstructive sleep apnea. Sleep Med 2009;10(3):368-373.

19. Kato M, Phillips BG, Sigurdsson G, Narkiewicz K, Pesek CA, Somers VK. Effects of sleep deprivation on neural circulatory control. Hypertension 2000;35(5):1173-1175.

20. Tochikubo O, Ikeda A, Miyajima E, Ishii M. Effects of insufficient sleep on blood pressure monitored by a new multibiomedical recorder. Hypertension 1996;27(6):1318-1324.

21. Dean E, Bloom A, Cirillo M, Hong Q, Jawl B, Jukes J, et al. Association between habitual sleep duration and blood pressure and clinical implications: a systematic review. Blood Press 2012;21(1):4557.

22. Taheri S, Lin L, Austin D, Young T, Mignot E. Short sleep duration is associated with reduced leptin, elevated ghrelin, and increased body mass index. PLoS Med 2004;1(3):e62.

23. Vorona RD, Winn MP, Babineau TW, Eng BP, Feldman HR, Ware JC. Overweight and obese patients in a primary care population report less sleep than patients with a normal body mass index. Arch Intern Med 2005;165(1):25-30.

24. Aghamohammadzadeh R, Heagerty AM. Obesity-related hypertension: epidemiology, pathophysiology, treatments, and the contribution of perivascular adipose tissue. Ann Med 2012; 44 Suppl 1:S74S84.

25. Eckel RH, Wassef M, Chait A, Sobel B, Barrett E, King G, et al. Prevention Conference VI: diabetes and cardiovascular disease. Writing Group II: pathogenesis of atherosclerosis in diabetes. Circulation 2002;105(18):e138-e143.

26. Schmid SM, Hallschmid M, Jauch-Chara K, Wilms B, Benedict C, Lehnert $\mathrm{H}$, et al. Short-term sleep loss decreases physical activity under free-living conditions but does not increase food intake under time-deprived laboratory conditions in healthy men. Am J Clin Nutr 2009;90(6):1476-1482.
27. Hong S, Dimsdale JE. Physical activity and perception of energy and fatigue in obstructive sleep apnea. Med Sci Sports Exerc 2003;35(7): 1088-1092.

28. Conroy RM, Pyo K, Backer GD, Bacquer DD, Ducimetie P, Keil U, et al. Estimation of ten-year risk of fatal cardiovascular disease in Europe: the SCORE project. Science 2003;24(1):987-1003.

29. Chalder T, Berelowitz G, Pawlikowska T, Watts L, Wessely S, Wright D, Wallace EP. Development of a fatigue scale. J Psychosom Res 1993;37(2):147-153.

30. Sadoul P. Assessment of functional respiratory deficit. Bull Eur Physiopathol Resp 1983;19(1):3-6.

31. Mancia G, De Backer G, Dominiczak A, Cifkova R, Fagard R, Germano G, et al. 2007 Guidelines for the management of arterial hypertension: the task force for the management of arterial hypertension of the European Society of Hypertension (ESH) and of the European Society of Cardiology (ESC). J Hypertens 2007;25(6): 1105-1187.

32. NICE. NICE guideline CG66: type 2 diabetes: the management of type 2 diabetes (updated May 2009). http://wwwniceorguk/CG66. Accessed March 17, 2012.

33. Williams B, Poulter NR, Brown MJ, Davis M, McInnes GT, Potter $\mathrm{JF}$, et al. Guidelines for management of hypertension: report of the fourth working party of the British Hypertension Society, 2004-BHS IV. J Hum Hypertens 2004;18(3):139-185.

34. Mignault D, St-Onge M, Karelis AD, Allison DB, Rabasa-Lhoret R. Evaluation of the Portable HealthWear Armband: a device to measure total daily energy expenditure in free-living type 2 diabetic individuals. Diabetes Care 2005;28(1):225-227.

35. Sedentary Behaviour Research N. Standardized use of the terms "sedentary" and "sedentary behaviours." Appl Physiol Nutr Metab 2012;37(3):540-542.

36. Tudor-Locke C. Steps to better cardiovascular health : how many steps does it take to achieve good health and how confident are we in this number? Curr Cardiovasc Risk Rep 2010;4(4)271-276.

37. Niiranen TJ, Hänninen MR, Johansson J, Reunanen A, Jula AM. Home-measured blood pressure is a stronger predictor of cardiovascular risk than office blood pressure: the Finn-Home study. Hypertension 2010;55(6): 1346-1351.

38. Asayama K, Ohkubo T, Kikuya M, Obara T, Metoki H, Inoue R, et al. Prediction of stroke by home "morning" versus "evening" blood pressure values: the Ohasama study. Hypertension 2006;48(4):737743.

39. O'Driscoll DM, Turton AR, Copland JM, Strauss BJ, Hamilton GS. Energy expenditure in obstructive sleep apnea: validation of a multiple physiological sensor for determination of sleep and wake. Sleep Breath 2013;17(1):139-146.

40. West SD, Kohler M, Nicoll DJ, Stradling JR. The effect of continuous positive airway pressure treatment on physical activity in patients with obstructive sleep apnoea: a randomised controlled trial. Sleep Med 2009;10(9):1056-1058.

41. Jakicic JM, Marcus M, Gallagher KI, Randall C, Thomas E, Goss FL, Robertson RJ. Evaluation of the SenseWear Pro Armband to assess energy expenditure during exercise. Med Sci Sports Exerc 2004;36(5):897-904.

42. Pitta F, Troosters T, Probst VS, Spruit MA, Decramer M, Gosselink R. Quantifying physical activity in daily life with questionnaires and motion sensors in COPD. Eur Respir J 2006;27(5):1040-1055.

43. Van Remoortel H, Giavedoni S, Raste Y, Burtin C, Louvaris Z, Gimeno-Santos E, et al. Validity of activity monitors in health and chronic disease: a systematic review. Int $\mathrm{J}$ Behav Nutr Phys Act 2012;9(1):84.

44. Van Remoortel H, Raste Y, Louvaris Z, Giavedoni S, Burtin C, Langer D, et al. Validity of six activity monitors in chronic obstruc- 


\section{Physical Activity and Blood Pressure in OSA}

tive pulmonary disease: a comparison with indirect calorimetry. PLoS One 2012;7(6):e39198.

45. Parati G, Stergiou GS, Asmar R, Bilo G, de Leeuw P, Imai Y, et al. European Society of Hypertension practice guidelines for home blood pressure monitoring. J Hum Hypertens 2010;24(12):779-785.

46. Bobrie G, Chatellier G, Genes N, Clerson P, Vaur L, Vaisse B, et al. Cardiovascular prognosis of "masked hypertension" detected by blood pressure self-measurement in elderly treated hypertensive patients. JAMA 2004;291(11):1342-1349.

47. Basta M, Lin HM, Pejovic S, Sarrigiannidis A, Bixler E, Vgontzas AN. Lack of regular exercise, depression, and degree of apnea are predictors of excessive daytime sleepiness in patients with sleep apnea: sex differences. J Clin Sleep Med 2008;4(1):19-25.

48. Garrigue S, Pépin JL, Defaye P, Murgatroyd F, Poezevara Y, Clémenty J, Lévy P. High prevalence of sleep apnea syndrome in patients with long-term pacing: the European Multicenter Polysomnographic Study. Circulation 2007;115(13):1703-1709.

49. Foster GD, Sanders MH, Millman R, Zammit G, Borradaile KE, Newman AB, et al. Obstructive sleep apnea among obese patients with type 2 diabetes. Diabetes Care 2009;32(6):1017-1019.

50. Hill JO, Wyatt HR. Role of physical activity in preventing and treating obesity. J Appl Physiol 2005;99(2):765-770.

51. Luke A, Dugas LR, Durazo-Arvizu RA, Cao G, Cooper RS. Assessing physical activity and its relationship to cardiovascular risk factors: NHANES 2003-2006. BMC Public Health 2011;11:387.

52. Pedrosa RP, Drager LF, Gonzaga CC, Sousa MG, de Paula LKG, Amaro ACS, et al. Obstructive sleep apnea: the most common secondary cause of hypertension associated with resistant hypertension. Hypertension 2011;58(5):811-817.

53. Chobanian AV, Bakris GL, Black HR, Cushman WC, Green LA, Izzo JL, et al. The Seventh Report of the Joint National Committee on Prevention, Detection, Evaluation, and Treatment of High Blood Pressure: the JNC 7 report. JAMA 2003;289(19):2560-2572.
54. Menotti A, Blackburn H, Kromhout D, Nissinen A, Adachi H, Lanti M. Cardiovascular risk factors as determinants of 25-year all-cause mortality in the seven countries study. Eur J Epidemiol 2001;17(4): 337-346.

55. Thorp AA, Owen N, Neuhaus M, Dunstan DW. Sedentary behaviors and subsequent health outcomes in adults a systematic review of longitudinal studies, 1996-2011. Am J Prev Med 2011;41(2):207215.

56. Pouliou T, Ki M, Law C, Li L, Power C. Physical activity and sedentary behaviour at different life stages and adult blood pressure in the1958 British cohort. J Hypertens 2012;30(2):275-283.

57. Savica V, Bellinghieri G, Kopple JD. The effect of nutrition on blood pressure. Annu Rev Nutr 2010;30:365-401.

58. Drager LF, Lorenzi-Filho G. CPAP for obstructive sleep apnea and the metabolic syndrome. N Engl J Med 2012;366(10):964; author reply $965-966$.

59. Hoyos CM, Killick R, Yee BJ, Phillips CL, Grunstein RR, Liu PY. Cardiometabolic changes after continuous positive airway pressure for obstructive sleep apnoea: a randomised sham-controlled study. Thorax 2012;67(12)1081-1089.

60. Awad KM, Malhotra A, Barnet JH, Quan SF, Peppard PE. Exercise is associated with a reduced incidence of sleep-disordered breathing. Am J Med 2012;125(5):485-490.

61. Giebelhaus V, Strohl KP, Lormes W, Lehmann M, Netzer N. Physical exercise as an adjunct therapy in sleep apnea: an open trial. Sleep Breath 2000;4(4):173-176.

62. Peppard PE, Young T. Exercise and sleep-disordered breathing: an association independent of body habitus. Sleep 2004;27(3): 480-484.

63. Sengul YS, Ozalevli S, Oztura I, Itil O, Baklan B. The effect of exercise on obstructive sleep apnea: a randomized and controlled trial. Sleep Breath 2011;15(1):49-56. 